\title{
E-Navigation or Autonomous Navigation - Quo vadis?
}

\author{
Nurma Karima Sari ${ }^{1, a, *}$, Michael Baldauf ${ }^{2, b}$ and Momoko Kitada ${ }^{3, c}$ \\ ${ }^{1}$ Ministry of Transportation of Indonesia, Jakarta, Indonesia \\ ${ }^{2}$ Maritime Risk and System Safety (MaRiSa) Research Group, World Maritime University (WMU), \\ Malmö, Sweden \\ ${ }^{3}$ Maritime Education and Training, Human and Organizational Development (METHOD) \\ Research Group World Maritime University (WMU), Malmö, Sweden \\ a.sarysaree@gmail.com /nurmakarima@dephub.go.id,b.mbf@wmu.se,c.mk@wmu.se \\ *corresponding author
}

Keywords: digitalization, e-Navigation, empirical study, human element, humanmachine interaction.

Abstract: The majority of accidents in the maritime domain is caused to by human errors. One of the measures to reduce human-related marine accidents is proposed to implement the eNavigation concept according to the International Maritime Organization's (IMO) strategy implementation plan. E-Navigation is harmonized collection, integration, exchange and presentation of information that facilitate berth to berth operations. To achieve this, the introduction of electronic means, including state-of-the-art information and communication technologies, is the key to support ship operators on-board as well as ashore. Considering the fact that around $50 \%$ of accidents occurring at sea are attributed to navigational challenges, a systematic maritime traffic management seems to be necessary. On the other hand, modern ship operations rely on a small number of crew whose responsibilities for safe and efficient navigation are increasingly high. Without operational support from the shore, using a reliable technology-based system, it would be challenging to reduce marine accidents. e-Navigation, provides a great potential to help mitigate incidents such as collisions, grounding problems, oil spills and piracy. It also allows a certain flexibility in utilizing both new and existing technologies which are acceptable within the operating standards. In this paper, the authors study the modus operandi of the proposed e-Navigation concept in terms of its requirements and implementation plans as well as the potential limitations and benefits around the concept. An empirical study was conducted through online questionnaires and structured interviews. The study provides insights into attitudes on the role and predicted efficacy of the implementation of e-Navigation towards the materialization of its concept by 2020. Finally, the paper proposes recommendations with regard to implementing this ambitious and challenging concept.

\section{Introduction}

The maritime industry has been facing a series of technological development in ship operation since the Age of Sail. Nowadays, modern ship operations especially in coastal areas with dense traffic are 
supported by shore-based personnel, including vessel traffic service (VTS) operators, port operators, and company operators. Containerization has brought a logistic evolution where efficiency has been sought in every aspect of ship operation and global supply chains. These industrial changes affected the size of crew on board. In the last couple of decades, the number of crew has been significantly reduced on cargo vessels, which is now typically 18 seafarers on a cargo ship between 2,000 and 7,999 GT [1].

Modern ship operations are supposed to increase the safety of ships, cargos, and people. However, there are still many marine accidents mainly caused by human errors in the era of advanced technology. As indicated by Weintrit [2] the combination of navigational errors and human failure indicate a potential failure of the main ship systems used for navigation and control, the performance of human machine interaction is questionable [3].

The concept of e-Navigation was developed by the International Maritime Organization (IMO) in close cooperation with the International Association of Marine Aids to Navigation and Lighthouse Authorities (IALA), inter alia, to improve the integrity and accuracy of information used by the maritime stakeholders. In order to support human machine interaction for safe operation of ships, this study focuses on how and to what extent the modus operandi of e-Navigation can be utilized. By using an online survey and interviews with key stakeholders, the paper identifies the role and predicted efficacy of the implementation of e-Navigation towards the materialization of its concept by 2020 .

\section{What is e-navigation?}

\subsection{The Definition}

The definition of e-Navigation is formally described as the harmonized collection, integration, exchange, presentation and analysis of marine information on board and ashore by electronic means to enhance berth to berth navigation and related services for safety and security at sea and protection of the marine environment [4]. Figure 1 contains the principle outline and basic elements of the eNavigation concept.

Referring to this IMO definition, it has to be highlighted that e-Navigation originally addresses ships and operation of ships falling under IMO's convention, especially the international convention on the Safety of Live at Sea (SOLAS). However, shipping on a worldwide scale is a composition of ships falling under this convention "SOLAS ships" and ships not falling under this convention "NonSOLAS ships". On the other hand, e-Navigation is a concept that not only addresses the ship's perspective but also covers all aspects of processes linked to shipping including shore-based monitoring and support for the purposes of ensuring a safe and efficient vessel traffic flow along the coasts from an to ports.

\subsection{The Development of e-Navigation}

Since the 81st session of IMO's Maritime Safety Committee (MSC 81) in 2006, which is commonly referred to as the official birth of the e-Navigation initiative and the beginning of the development of that concept, until now, the involved stakeholders and all maritime users are continuously further developing the concept for smooth and comprehensive implementation. The materialization of the concept itself is set to be completed by 2020. Some countries in the European and Asian region have already started to implement this concept, by establishing testbed areas using developed prototypes under real conditions. 


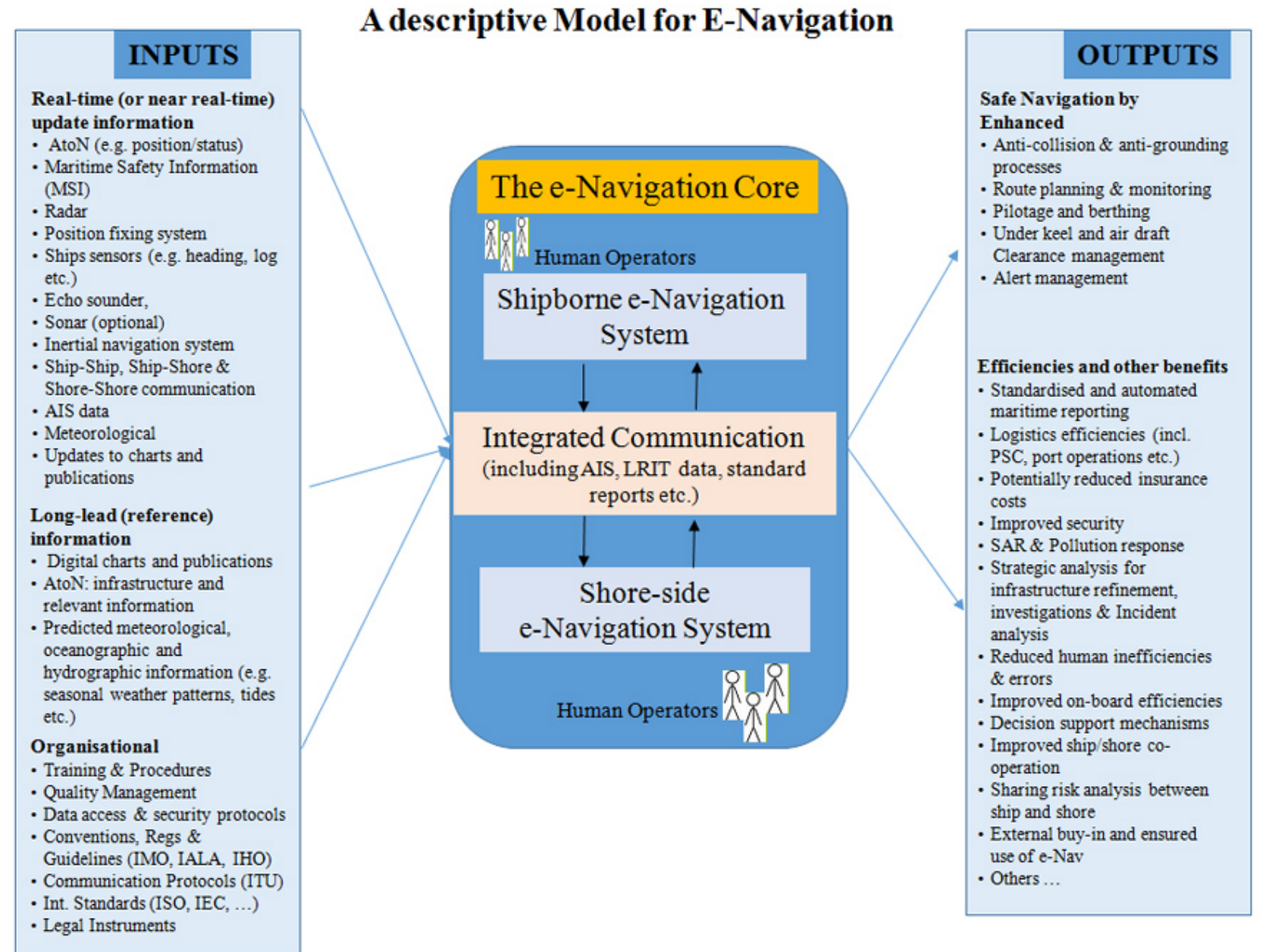

Figure 1: A descriptive model of e-Navigation (adapted from IMO/IALA documents).

\subsection{Risk Control Options and MSPs}

One component of the e-Navigation concept, presently of highest relevance is the established Strategic Implementation Plan (SIP). This plan, among others, calls for comprehensive and profound gap analysis through Formal Safety Assessment (FSA) in order to identify and form the core of eNavigation which are 7 Risk Control Options (RCOs) together with 16 Maritime Service Portfolios (MSPs). The RCOs and MSPs are established to pursue the five (out of nine) prioritized e-Navigation solutions and sub solutions (Figure 2).

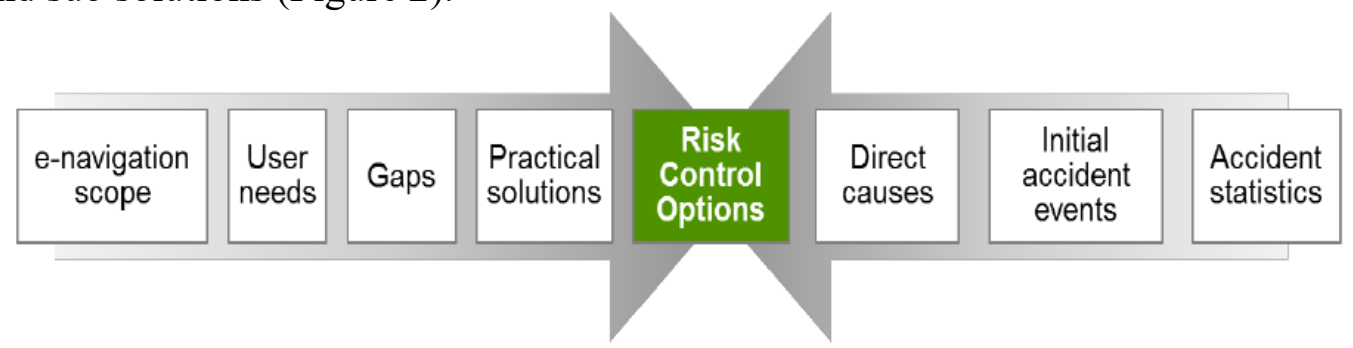

Figure 2: RCO Identification Process (NAV 59/6). 


\section{Is E-Navigation Disruptive Technology?}

We live in the beginning of the era of disruption, where the desire of "instant and fast" communication started to grow up. The change in our daily communication in terms of its speed and convenience can be seen as a result of a worldwide development and competition in Information and Communication Technology (ICT). Each organization or company race to become an innovator. Meanwhile, users of all kind of domains, are constantly challenged to use this technology effectively. The maritime sector has introduced e-Navigation as a new way of communication between the numerous different involved parties that offer a seamless-way. But is this concept benefitting the industry or vice versa? It seems, however, the vibrant of e-Navigation concept is to become a problem solver for the complex tasks related to marine transportation and sea navigation.

Christensen [5] stated that the technology can be divided into the two types "sustaining" and "disruptive". As indicated by Rouse[6], sustaining technology relies on incremental improvements to an already established technology, while disruptive technology lacks refinement, often has performance problems because it is new, appeals to a limited audience and may not yet have a proven practical application. In this sense e-Navigation can be seen as an attempt to provide disruptive solutions by applying latest ICT solutions for instance in system integration but facing the problem of a widely inconsistent existing technical infrastructure. A good sample might be the introduction of the Electronic Chart Display and Information Systems (ECDIS). The electronic "sea chart" is to replace the traditionally used paper chart. Navigators will no longer need to take care for indicating the actual position in the chart but can check in the display the progress of the voyage and if the ship keeps the planned route at all times.

There is clear potential for many other functions and services. However, for several reasons ECDIS, although being made mandatory for SOLAS ships, nowadays is still "coexisting" with paper charts. ECDIS is considered to be one core element integrating a huge amount of the data and information flows needed for the implementation of the e-Navigation concept on-board ships as well as ashore.

However, in relation to the currently ongoing developments in respect to autonomous navigation and even unmanned shipping, e-Navigation as a whole is a concept that focuses on the human operators involved in processes onboard or ashore providing assistance for improved situational awareness and decision making. Systems and services under development or tested, like e.g. "Route exchange", "Augmented Reality and Head-Up Displays" or "Dynamic Manoeuvre Prediction" let the human in the loop and considers the change of skills and knowledge that is needed to make eNavigation smoothly functioning[7]. In this respect e-Navigation clearly is "sustaining technology".

\subsection{Issue of Mixed Environment}

Current research on e-Navigation [8] demonstrated the implementation of the e-Navigation concept on a global and even on a regional level strongly depends on the provision of a harmonized infrastructure and environment.

With regard to the link between shore-based services and their link to on-board process it the shorebased e-Navigation part is defined as it stated on MSC 85/26/Add.1 Annex 20 as the management of vessel traffic information and related services from ashore enhanced through better provision, coordination and exchange of comprehensive data formats that will be more easily understood and utilized by shore-based operators in support of vessel safety and efficiency.

In this way, e-Navigation will allow for a much more enhanced management of the traffic flow, however, the prerequisites need to be very well studied in advance. Such investigations need to take into consideration the three sides of the "e-Navigation coin", when looking at Figure 2: the shipborne and the shore-side systems as well as the connecting integrated communication. On the one hand it is 
expected to have a wide spectrum of technology-driven technical solutions for new functions and systems on the ship-end and on the shore-side end. Integrated communication will depend on existing technical infrastructure (availability and abilities of communication networks, broadband, satellite etc.) and geographical conditions in the respected areas (dimensions, topographic, hydrographic, climate and other characteristics). It is obvious that the all these parameters are varying significantly for each specific region.

\section{Methods}

This research [8] uses qualitative methods, online interviews with the key stakeholders. As it stated by Lützhöft[9], quantitative data may be useful in measuring attitude across a large sample, but paper interviews perform a powerful framework to learn about individual's perception based on their skills, knowledge, and experiences. Similarly with Marshall and Rossman[10], there are the advantage of qualitative methods, such as valuing participant's perspectives, focusing on everyday life experiences, enquiry and primary descriptions. By applying qualitative research methods, the research aimed to collect the responses emanating from the experiences of the participants.

The participants are selected from those key personnel who have been instrumental to the processes of e-Navigation. Members of international maritime organizations such as IALA, IMO, The Nautical Institute, CIRM, and officials of the maritime administrations were invited to participate. The participants' nationalities are diverse, for example, Australia, Canada, Denmark, Germany, Norway, Republic of Korea, United Kingdom, United States, Singapore, and Sweden. These interview candidates were recruited through the WMU and IMO professional networks, as well as the candidate's publication on e-Navigation development. During the research, a total of 23 experts/stakeholders were chosen for interviews; 14 out of 23 participants confirmed their participation by sending back their answers via email.

The online interviews were conducted during May - August 2017. The interview questions were divided into five sections bearing two parts: background review and technical and/or working conditions. The researcher transcribed interviews and analyzed them on a comparative and narrative basis. In addition to online interviews, informal interviews were used to listen to the voices of maritime users, experts and scholars in some particular fields relevant to the topic, such as cyber security. Personal notes were recorded for comparison with the online interview results and SIP to deepen our understanding on e-Navigation.

\section{Data Analysis}

The total of 14 interviewees identified themselves by the level of e-Navigation technical knowledge as basic $(n=3,22 \%)$, intermediate $(n=2,14 \%)$, and advanced $(n=9,64 \%)$. All of them were working directly in the development of e-Navigation with publication records in academic journals or professional magazines as well as presentations at e-Navigation seminars organized by IALA or IMO. This fact ensures the quality of research data obtained from those e-Navigation experts who can provide the most relevant information relating to e-Navigation.

Through the qualitative analysis of interview data, several issues emerged as challenges of implementing e-Navigation. These challenges are related to data/information integrity; acknowledgement of received information; traditional skill loss; and two-tier society. 


\subsection{Data/ Information Integrity}

The first challenge of implementing e-Navigation was described by 6 interviewees (42\%) as its data/information integrity. Suppose that vessels in the same area have "different" information (e.g., one vessel has the current information and the others do not, or all but one vessel is up-to-date) which could happen due to their onboard equipment capabilities. A risk of casualty will then increase as one interviewee represents a common concern that:

First, data communication delays can create situations in dynamic areas that could result in conflicts due to updates not being received in time. This would be the case with just-in-time arrival technology as a significant delay in a changed arrival time might mean two ships arrive at the same time, causing congestion. Secondly, unverified decision support services could provide wrong suggestions that could result in an accident.

It is in fact not all vessels that will participate in the e-Navigation concept, because the enforcement of e-Navigation for all vessels is currently not possible due to non-SOLAS vessels. From the perspective of flag states, they are responsible for ensuring that their vessels of all sizes have an eNavigation awareness. It is also problematic that not all coastal states will provide all e-Navigation services. Hence it is difficult to achieve data/information integrity in e-Navigation.

\subsection{Acknowledgement of Received Information}

There is also a design problem in the current e-Navigation in terms of how it communicates with users. All interviewees agreed that e-Navigation so far does not acknowledge messages sent. This design problem triggers a concern of how the operator can be sure that all vessels have received the information. The more critical the sent information is, the more important the acknowledgement or receipt of the information will be. It is suggested that this potential deficit can be resolved by having a message acknowledgment that can be recorded within a journal database shared by all stakeholders.

\subsection{Traditional Skill Loss}

The third challenge is rather a long-term effect of e-Navigation on seafarers' traditional skills. Seafaring has a long tradition and various knowledge, skills, and techniques have been generated and tested over the centuries. Art of navigation is still taught in maritime education and training institutions around the world. The heritage of ship handling is highly valued from the anthropological and historical viewpoints.

However, although e-Navigation is clearly focusing on the human element and by definition aiming at the support of human operators ashore as well as onboard, the practices provide the processes to alert a seafarer if they are not functioning correctly. Consequently, this may create a risk that the operators might be over-dependent on automated systems and give away their traditional skills. Several interviewees oversee a change in seafarers' work patterns onboard. For example, some kind of automation on the bridge will no longer require a skilled officer on watch (OOW) to maintain 24 hours of watch.

Similarly, five interviewees agreed that the convenience of e-Navigation concept would potentially result in over-reliance and dependence on automated systems on board, which may lead to the loss of situational awareness, and eventually traditional navigation skills which used to reside in the heart of seafarers. In the traditional way of seafarers' work, there are several opportunities to check the progress of route planning and cross-reference the position of waypoints with the planned course as the voyage proceeded. This plan-do-check process helps seafarers to foster situational awareness to 
avoid risks ahead of them. Over-reliance on e-Navigation that given data and information must be in high reliability can loosen seafarers' attention and caution towards potential risks.

In order to address those concerns, it seems to be reasonable to require, that integration of new technologies and enhanced functions needs to be very well specified in order to meet the human operators' needs. For instance, implementation of new warnings shall stimulate and inspire operators to perform in such a way, that triggering of a warning or an alarm is avoided by good practice rather than being distracted by an alert that is lacking of sufficient situational context [11].

Considering the shore-side elements of the maritime transportation system, there seems to be an obvious impact on operators dealing with traffic monitoring and providing the services from shorebased VTS. Degenerating or even lacking of traditional skills and knowledge that are often taken as prerequisites for recruiting VTS operators, may result in a lower level of quality or in another kind of support for on-board decision making.

\subsection{Two-Tier Society}

Finally, no matter how good the e-Navigation concept is, if not all of the maritime stakeholders follow nor align their approach to the same goal, it may create a chaos in the global maritime industry. Some ships are fully integrated to e-Navigation while others are partly integrated or not at all. It will cause a confusion and the concept of e-Navigation may fail. Such anticipation is not unfortunately imaginary, because for example, there will be ships under SOLAS and others not. This inevitably unequal environment will create a two-tiered maritime society: the compliant vessels and the noncompliant vessels. The availability of information, then, depends on whether a ship is equipped with e-Navigation. Inequality in access to safety information may result in a tragedy. Two vessels of similar sizes may have completely opposite destinies: one ship has a better chance to survive and the other suffers from the lack of safety information. At least, that is not what e-Navigation was initially designed and promised us.

\section{Conclusion}

The paper provided a preliminary analysis on how the concept of e-Navigation can be better in place under the current operational practices in the maritime industry. To do this, the study focused on the modus operandi of the e-Navigation concept. A qualitative analysis on transcribed interview data from the e-Navigation experts includes rich insights in terms of how to materialize the e-Navigation concepts.

While acknowledging a number of benefits in the e-Navigation concept, such as improved safety of navigation, better protection of marine environment, augmented security, and increased operational efficiency among others, there are also anticipated challenges in its implementation. From the empirical data, the paper highlighted four challenges, including data/information integrity; acknowledgement of received information; traditional skill loss; and two-tier society. The study also found the importance of acknowledging non-SOLAS vessels within e-Navigation.

In the era of disruptive technologies, asserting the arrival of autonomous systems in the near future, it is time to reconsider the way of human-machine interactions to improve the safety operation of ships. An extreme version of autonomous systems, such as unmanned ships, will still require human interventions under the current regulatory framework. With e-Navigation, seafarers need to comprehend and analyze such digital data to be able to safely navigate their vessels. Naturally, maritime education and training need to be evolved in order to meet the future demands of maritime skill sets. 
Though the research has a limitation of knowing other perspectives, for example, seafarers and shore-based operators. In order to address such aspects comprehensive studies, including e.g. simulation based experiments are needed to fill this gap. So far, first preliminary studies on interaction of autonomously navigating ships in VTS controlled areas have been conducted and delivered some principle trends and hints [12] and are useful for further refinement for more detailed follow-up research.

The research presented in this paper provided a comprehensive picture on the modus operandi of the e-Navigation concept. The future research can look at good practices by onboard and shore-based operators and how the e-Navigation concept is possibly well-adopted and operationalized to achieve successful implementations.

\section{Acknowledgements}

Some parts of the research work and results presented in this paper belong partly to WMU's project on further development and implementation of the e-Navigation concept funded by Korea Research Institute Ships \& Ocean Engineering (KRISO) as well as the European project for research and technological development "OpenRisk", co-financed by the EU - Civil Protection Financial Instrument as project 2016/PREV/26.

\section{References}

[1] JITI and N. Foundation, A study on the "Future global supply and demand for seafarers and possible measures to facilitate stakeholders to secure a quantity of quality seafarers. Tokyo: Japan International Transport Institute and the Nippon Foundation, 2010.

[2] A. Weintrit, "e-Nav, Is It Enough?," Transnav: International Journal On Marine Navigation and Safety of Sea Transportation, vol. 10, pp. 567-574, 2016.

[3] S. Lee, N. Lemon, and M. Lützhöft, "Harmonizing Guidance for Future Ship Navigation Systems, "Sea Technology, vol. 56, pp. 41-44, 2015.

[4] IMO, "Strategy for The Development and Implementation of e-Navigation," London2008.

[5] C. M. Christensen, The innovator's dilemma: when new technologies cause great firms to fail. Boston: Harvard Business School Press, 1997.

[6] M. Rouse. (2016, December) disruptive technology.

[7] M. Baldauf, "ACCSEAS Training Needs and Gap Analysis Report. Review of the Present Situation and Approach to Training Needs Analysis," 2015.

[8] N. K. Sari, A Study on e-Navigation Modus Operandi. Malmö, Sweden: World Maritime University, 2017.

[9] M. Lützhöft, The technology is great when it works: Maritime technology and human integration of the Ship's Bridge. Linköping, Sweden: University of Linköping, 2004.

[10] C. Marshall and G. B. Rossman, Designing qualitative research. Los Angeles, USA: Sage Publication, 1999.

[11] M. Baldauf, R. Mehdi, S. Fischer, and M. Gluch, "A perfect warning to avoid collisions at sea?," 52 Scientific Journals of the Maritime University of Szczecin, pp. 53-64, 2017.

[12] M. Baldauf, M. Kitada, R. Mehdi, and D. Dalaklis, "E-Navigation, Digitalization and Unmanned Ships: Challenges for Future Maritime Education and Training," in Proceedings, 12th International Technology, Education and Development Conference Valencia, IATED, Spain, 2018, pp. 9525-9530. 